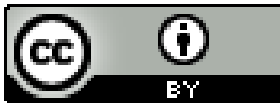

\title{
AGUERRIDOS PROFESSORES POLÍTICOS E ABOLICIONISTAS: EDUCAÇÃO, DOCÊNCIA E SOCIABILIDADES NO IMEDIATO PÓS-ABOLIÇÃO
}

Jucimar Cerqueira dos Santos

Fabiano Moreira da Silva ${ }^{2}$

Sivaldo dos Reis Santos ${ }^{3}$

Resumo: Este texto tem o objetivo de discutir a atuação e a relevância de três professores na escolarização para pessoas livres, libertas e escravizadas na realidade social do final do século XIX e início do século XX. Antônio Bahia da Silva Araújo, Cincinato Ricardo Pereira da Franca e Francelino de Andrade também escreveram em jornais de grande circulação, foram políticos e lideranças de associações abolicionistas em defesa de "sujeitos comuns". Em que medida estes professores buscaram outros lugares sociais para si e para seus alunos, bem como melhorias na educação baiana através das instituições que fizeram parte? As fontes para a tal análise foram ofícios da Instrução Pública da Bahia do Arquivo Público do Estado da Bahia e do Arquivo Municipal de Salvador, bem como de jornais, dos Annais da Assembleia legislativa da Bahia e da Hemeroteca Digital da Biblioteca Nacional.

Palavras chaves: Educação, Sociabilidades, Pós abolição

\section{SUCCESSFUL POLITICAL TEACHERS AND ABOLICIONISTS: EDUCACTION, TEACHING AND SOCIABILITIES IN THE IMMEDIATE POST-ABOLITION}

\footnotetext{
${ }^{1}$ Doutorando (UFBA) em História Social da Educação da População Negra. Atuação na Educação Básica, em cursos socioeducativos no sistema fechado, em projetos de prevenção a suicídio em escolas estaduais de Salvador, formação de professores de Ciências Humanas e elaboração de cadernos pedagógicos. E-mail: jucimar18@yahoo.com.br
}

\begin{abstract}
${ }^{2}$ Mestre e Licenciado em História pela Universidade Federal da Bahia. Especialista em Tecnologias na Aprendizagem pelo Centro Universitário do Senac. Bacharel em Administração de Empresas pelo Instituto Federal da Bahia. Especialista em Gestão Estratégica de Pessoas pela Universidade Estadual da Bahia. Atuação como professor do ensino médio pela Secretaria de Educação da Bahia. E-mail: fabianomdasilva@hotmail.com

3 Licenciado e Mestre em História Social- Universidade Federal da Bahia. E-mail: srsvaldosa321@gmail.com
\end{abstract}

Revista da ABPN • v. 12, n. Ed. Especial - Caderno Temático: "Africanos, escravizados, libertos biografias, imagens e experiências atlânticas” • agosto de 2020, p. 591-612 
Abstract: This text aims to discuss the role and relevance of three teachers in schooling for free, liberated and enslaved people in a social reality of the late 19th and early 20th centuries. Antônio Bahia da Silva Araújo, Cincinato Ricardo Pereira da Franca and Francelino de Andrade also wrote in newspapers of great circulation, were politicians and leaders of abolitionist associations in defense of "common subjects". To what extent did these teachers seek other social places for themselves and their students, as well as improvements in Bahian education through the institutions that were part of it? The sources for this analysis were letters from the Bahia Public Instruction of the Public Archive of the State of Bahia and the Municipal Archive of Salvador, as well as newspapers, from the Annais of the Legislative Assembly of Bahia and of the Digital Library of the National Library.

Keyswords: Education, Sociabilitys, Post abolition

\section{EXITOSOS PROFESORES Y ABOLICIONISTAS POLÍTICOS: EDUCACIÓN, ENSEÑANZA Y SOCIABILIDADES EN LA POST-ABOLICIÓN INMEDIATA}

Resumen : Este texto tiene como objetivo discutir el papel y la relevancia dos tres maestros en la escolarización de personas libres, liberadas y esclavizadas en una realidad social de finales del siglo XIX y principios del XX. Antônio Bahia da Silva Araújo, Cincinato Ricardo Pereira da Franca y Francelino de Andrande también escribieron en periódicos de gran circulación, eran políticos y líderes de asociaciones abolicionistas en defensa de 'hombres comunes'.¿En qué medida estos maestros buscaron otros lugares sociales para ellos y sus alumnos, así como mejoras en la educación bahiana a través de las instituiciones de las que formaban parte ? Las fuente para este análisis fueron cartas de la Instrucción Pública de Bahia del Archivo Público del Estado de Bahía y del Archivo Municipal de Salvador, así como de periódicos, de los Annais de la Asamblea Legislativa de Bahía y de la Biblioteca Digital de la Biblioteca Nacional.

Palabras clave: Educación, Sociabilidades, Posterior a la abolición

\section{ENSEIGNANTS POLITIQUES ET ABOLICIONISTES RÉUSSIES: ÉDUCATION, ENSEIGNEMENT ET SOCIABILITÉS DANS LA POST- ABOLITION IMMÉDIATE}

Résumé: Ce texte a pour objectif de discuter le rôle trois enseignants dans la scolarisation des personnes libres. Libérées, et escravisées dans le but de souligner leur pertinence dans la perspective d'une réalité sociale sans esclavage entre la fin du XIXe sièlce et le début du XXe siècle. Antônio Bahia, Cincinato Franca et Francelino de Andrade ont également écrit dans des journaux largement diffusés, étaient des hommes politiques et des dirigeants d`associations abolitionistes et émancipatrices du front em faveur de « sujets communs ». Dans quelle mesure ces enseignants ont-ils cherchéc d'autres lieux sociaux pour ces matières, ainsique des améliorations dan l'enseignement bahianais ? Les sources

Revista da ABPN • v. 12, n. Ed. Especial - Caderno Temático: "Africanos, escravizados, libertos biografias, imagens e experiências atlânticas" • agosto de 2020, p. 591-612 
de cette analyse étaient des lettres de l'Instruction Publique de Bahia des Archives Publiques de l'État de Bahia et des Archives Munucipales de Salvador, ainsi que dés journaux, des Annales de L'Assemblée législative de Bahia et la Bibliotèque numérique de la Bibliothéque nationale

Mots-clés: Education, Sociabilités, Post abolition

O cenário da educação no Brasil tinha o analfabetismo e a busca para combatêlo como uma das principais questões do século XIX. A partir de 1827, muitas medidas foram tomadas para constituir uma educação pela institucionalização do setor da Instrução Pública que se apresentava como um dos elementos da nação em construção. Após essa espécie de "marco zero" da educação no Brasil politicamente independente, algumas prerrogativas foram elaboradas através de reformas educacionais, fosse provincial ou imperial, como as reformas imperiais de 1854 e a de 1879 (GONDRA e SCHUELER, 2008)

$\mathrm{Na}$ segunda metade do mesmo século também começaram a existir maiores formas de controle da população escravizada e liberta, entre elas, algumas escolas voltadas para trabalhadores e trabalhadoras na década de 1870. Havia também a ampliação do que se considerava vadiagem e o recrutamento forçado para forças armadas, principalmente, a marinha (LIMA, 2015). Há uma historiografia que apresenta experiências de educação para esses sujeitos por diferentes formas, desde aprendizagens da leitura e escrita em ambientes privados até casos de escravizados que foram matriculados em escolas públicas, quando alguns decretos provinciais e imperiais proibiam (SANTOS, 2017). Ao mesmo tempo, leis gradativas iam finalizando a escravidão sistêmica, quando findava a guerra contra o Paraguai, movimentações para implantação de uma República, como a fundação do Partido Republicano em 1870. Nesse tempo, ocorriam discussões cada vez maiores em torno da mão de obra no país, sobre o direito do voto e de propriedade (SCHUELER, 1997; FONSECA, 2000; BARROS, 2005; SOUSA 2006; LUCINDO, 2010; SANTOS, 2017).

$\mathrm{Na}$ Bahia, uma das reformas que visavam atender a escolarização para pessoas das camadas mais pobres e combater o analfabetismo foi a de 1870, que previa melhor

Revista da ABPN • v. 12, n. Ed. Especial - Caderno Temático: "Africanos, escravizados, libertos biografias, imagens e experiências atlânticas" • agosto de 2020, p. 591-612 
formação para os professores e professoras e escolas para "aqueles que na infância vedaram-lhes o livro", como afirmou o presidente provincial da época, Francisco Gonçalves Martins (MARTINS, 1869). Um dos elementos dessa reforma que surtiu efeito especificamente no ano da lei Rio Branco, em 1871, também chamada de ventre livre, foi a criação de escolas noturnas para homens trabalhadores diurnos, a partir dos 14 anos. Essa foi uma escolarização que aconteceu em várias províncias do Império, em algumas delas constavam as matrículas de libertos e escravizados (SCHUELER, 1997; LUZ, 2001; SOUSA, 2006; LUZ, 2008; LOPES, 2012; MAC CORD, 2012; SANTOS, 2017)

A reforma educacional imperial com decretos em 1878 e em 1879, chamada Carlos Leôncio de Carvalho, nome do ministro e secretário de Estado dos Negócios do Império responsável pela administração das questões relativas à educação, determinava mais possibilidades de libertos estudarem. Mas, continuava a proibição de escravizados se matricularem em escolas públicas desde a Constituição de 1824(SANTOS, 2017). Essa possibilidade aos libertos evidencia mais uma medida que garantia a oportunidade de escolarização a pessoas que, geralmente, não integravam as elites, o que pode ser resultado de manifestações deles e/ou de sujeitos ligados a políticas que defendiam causas que os contemplassem.

O decreto de 1878 foi o que oficializou as escolas noturnas no Império. Nele constava que essas escolas deveriam ser de primeiras letras para aprender a ler, escrever e contar, basicamente. Para cada escola diurna deveria ter uma noturna para homens a partir de 14 anos, daí não existir, oficialmente, a possibilidade de mulheres também terem direito a esse tipo de escolarização, o que significa uma limitação de escolas para trabalhadoras em um país com maioria de pessoas analfabetas (CARVALHO, 1878).

No final do ano letivo dessas escolas, para os alunos habilitados para exame de conclusão, os professores deveriam comunicar ao delegado da Instrução Pública que fosse marcado o dia e hora da prova. Caso fossem aprovados, seriam indicados para atividades com preferência aos lugares de serventes, guardas, correios, ajudantes de porteiro, porteiros das repartições, estabelecimentos públicos e outros empregos de igual categoria para os cidadãos que, reunindo os demais requisitos precisos, apresentarem notas de

Revista da ABPN • v. 12, n. Ed. Especial - Caderno Temático: "Africanos, escravizados, libertos biografias, imagens e experiências atlânticas" • agosto de 2020, p. 591-612 
aprovação plena obtida nos exames finais de algum curso público de instrução primária de adultos (CARVALHO, 1878). Segundo Eliane Peres (2001), esse decreto foi o mais importante para a criação de cursos noturnos. Ele estava circunscrito em um contexto em que sete anos antes tinha sido assinada a Lei do Ventre Livre e de dez anos antes da abolição da escravidão. Isso equivale a dizer que tais cursos foram criados e se expandiram no auge da discussão abolicionista ou até mesmo decorrente dela.

O decreto educacional de 1879, sobre a parte referente ao ensino primário, nível escolar de maior atuação dos três professores deste texto, apresenta inicialmente seus tons liberais ao anunciar em seu primeiro ponto que o ensino era completamente livre, salvo a inspeção necessária para garantir as condições de moralidade e higiene. Essa inspeção foi bastante criteriosa de forma a deixar o governo ciente de todos as coisas que aconteceriam nas escolas, seu regramento se desmembrou em incisos que evidenciam as intenções de vigilância do Estado sobre a educação e/ou a negligência de quem atuava diretamente nas escolas (CARVALHO, 1879).

Esse decreto propôs que o governo pudesse contratar professores particulares nas províncias, por intermédio dos respectivos presidentes provinciais, anualmente em localidades “e, demorando-se em cada uma delas o tempo preciso" para reunir os meninos e meninas da vizinhança para lhes darem os rudimentos do ensino primário, assim como ficou previsto criar ou auxiliar nas províncias cursos para o ensino primário dos adultos analfabetos (CARVALHO, 1879). Tais medidas traziam "ares" de que a educação no país aconteceria de forma ampla e eficaz, resolvendo seu maior problema: o analfabetismo.

Outro ponto dessa reforma foi a obrigatoriedade do ensino aos "dois sexos, feminino e masculino, com idades de 7 a 14 anos a partir de matrículas em escolas públicas”. Com esse regramento percebe-se que pessoas ingênuas e escravizadas nessa faixa etária estavam incluídas nessa obrigatoriedade, já que integravam a categoria de indivíduos. Enfim, os decretos educacionais de 1878 e 1879 evidenciam que havia iniciativas partindo do governo que estavam "olhando" para um projeto liberal republicano de educação nacional, assim como verifica-se nos casos das perspectivas do professor Antônio Bahia e Cincinato Franca, mesmo esses decretos sendo publicados vinte anos antes de findar o Império.

Revista da ABPN • v. 12, n. Ed. Especial - Caderno Temático: "Africanos, escravizados, libertos biografias, imagens e experiências atlânticas" • agosto de 2020, p. 591-612 
Medidas escolares possibilitavam que livres, libertos e escravizados pudessem aprender as primeiras letras, sair da condição de baixo letramento ou de analfabetismo, qualificando-se, em alguma medida, para o trabalho. Havia também a possibilidade de qualificarem-se para a vida, caso buscassem aproveitar essas medidas em proveito próprio, além de servir a algum patrão ou senhor. A preocupação de libertos em escolas havia na medida em que a matrícula só era efetivada para eles mediante apresentação de uma guia emitida pelos delegados da Instrução Pública, na qual constasse, além de outros dados, a profissão e a residência do matriculando, como se esses sujeitos trouxessem em si a criminalidade por ter vivido o cativeiro que lhes foi imposto, um indicativo dos estigmas raciais típicos da época. Nos casos desses estudantes serem pessoas escravizadas, era preciso que tivessem a permissão de seus senhores (SANTOS, 2017).

É nesse contexto que os três personagens escolhidos para esse texto iniciaram suas atuações docentes em prol das camadas populares, bem como outros professores, inclusive, em outras províncias fizeram. Entre os exemplos, há o da escola para pessoas de cor criada pelo professor Pretextato Silva, que foi solicitado por pessoas que não queriam mais que seus filhos passassem por discriminação em outras escolas do Rio de Janeiro (SILVA, 2000) e (FERREIRA, 2018), o do professor Hemetério Santos no final do século XIX no Rio de Janeiro, (SILVA, 2015) e Zé Índio, também no Rio de Janeiro (SILVA, 2020).

\section{ANTÔNIO BAHIA DA SILVA ARAGÃO}

Antônio Bahia destacou-se entre os professores envolvidos nos debates e na atuação para mais oportunidades de educação escolar para as camadas populares entre o final do século XIX e início do século XX. Ele se formou aluno mestre em $1870^{4}$ e já integrava o setor de Instrução Pública da Bahia (seria o que hoje é a Secretaria Estadual de Educação). Lotado na cidade de Cachoeira, certamente nas redondezas de onde nasceu, no Recôncavo baiano. O ano de 1870 foi o mesmo ano da reforma educacional que

\footnotetext{
${ }^{4}$ Assim se chamava o professor recém-formado pela Escola Normal Instituição de formação do magistério primário criada na década de 1830.
}

Revista da ABPN • v. 12, n. Ed. Especial - Caderno Temático: "Africanos, escravizados, libertos biografias, imagens e experiências atlânticas” • agosto de 2020, p. 591-612 
incentivava a criação de escolas noturnas públicas e particulares na província, assim como buscava-se exigir maior disciplina e melhor formação dos professores (MARTINS, 1870).

Antônio Bahia, além da prática da sala de aula diurna foi criador, professor e diretor da primeira escola noturna de Cachoeira em 1874 (SOUSA, 2006). Como grande parte da população dos trabalhadores do campo e de ofícios manuais do Recôncavo e de Salvador eram pessoas de cor, entre livres, libertos e escravizados, supõem-se que considerável contingente dessa escola era composto por esses tipos de trabalhadores

Antônio Bahia esteve em um longo debate, já na condição também de deputado estadual pelo Partido Liberal, a favor do projeto de reformulação das escolas noturnas, as quais passavam por constantes oscilações de financiamento e frequência em 1888, ano exato da lei de abolição da escravidão. Juntamente com o deputado Isaias Guedes de Melo, ele defendeu que escolas noturnas fossem criadas para pessoas egressas da escravidão de maneira ampla e sistematizada a partir do setor de Instrução Pública do governo da Bahia. Defendiam que existissem, pelo menos, uma dessas escolas em cada município e que atendessem às especificidades de seu público, inclusive, à dificuldade de frequentar as aulas que muitos alunos tinham por conta das demandas de trabalhos diurnos. Tais argumentos em defesa da reformulação das escolas noturnas demonstram ser embasados, provavelmente, no decreto imperial de 1878, que as oficializava no Brasil (SANTOS, 2017).

Após longo debate e resistência de deputados do Partido Conservador, o projeto foi aprovado e as escolas noturnas passaram ter ainda mais vulto na Bahia. Antônio Bahia continuou em defesa de uma escolarização ampla para as camadas populares e passou a ter muito mais cautela nos processos de elaboração e discussão de projetos para criação e/ou sistematização de questões ligadas à educação, pois ela passava a ser vista como uma das questões mais prolíferas da República em elaboração.

Segundo o historiador José Augusto da Luz (2008, p234), “a escola era o principal instrumento da utopia de civilização para o progresso, normatização, disciplina, moralização e para a formação do cidadão". Esse discurso parecia funcionar também como uma retórica política para conquista de votos de simpatizantes e para reformulações

Revista da ABPN • v. 12, n. Ed. Especial - Caderno Temático: "Africanos, escravizados, libertos biografias, imagens e experiências atlânticas” • agosto de 2020, p. 591-612 
dos mandos do tempo da escravidão, pois os índices educacionais, principalmente, referente ao analfabetismo no país continuavam baixos. Muitos políticos também eram proprietários de escravizados e/ou de terras, logo, negociar as relações de trabalho após a lei abolição da escravidão seria uma estratégia de manter suas finanças e evitar conflitos com trabalhadores que saiam de uma condição de sujeição degradante que poderiam se rebelar (ALBUQUERQUE, 2009). Para essa época, fica evidente que muitos grupos elitistas entendiam como necessário disciplinar as classes populares porque sem essa intervenção não seria possível inserir grupos dessas classes no modelo de "modernidade", “ordem e "progresso" defendidos para a República no país. Defender a escolarização somente no nível das primeiras letras (ensino primário) dessas classes poderia significar também mais possibilidade de garantias da subalternidade delas (SANTOS, 2017).

Sobre a maior cautela de Antônio Bahia nos debates que defendia a educação para as camadas populares na Assembleia legislativa, ele foi um dos destacados interlocutores de outro debate sobre escolas para trabalhadores. Em 1894, se discutia o deferimento da criação de uma escola de viticultura (cultivo de uva para vinho) na região norte da Bahia, onde hoje fica a cidade de Senhor do Bonfim. Ela seria financiada pelo estado e também pela iniciativa privada. Antônio Bahia discordou do governo estadual ser uma das fontes de financiamento dessa escola já que o projeto partia de interesses particulares (BAHIA, 1894).

Ele questionou também o parecer positivo para a criação dessa escola, pois defendia a municipalização do ensino da Bahia, o que concentrava toda gestão escolar para as cidades e não o estado. Para o deputado e professor, prevalecer aos cuidados do estado à instância da educação incorria em risco de mais precarização educacional, se comparado como acontecido em anos anteriores. (ALB,1894). ${ }^{5}$ A criação da escola foi aprovada do mesmo jeito que foi deferido o seu financiamento. Antônio Bahia não teve sua ressalva aceita pela maioria dos deputados, mas pontuou significativamente que queria muito que a escola realmente alcançasse pessoas das camadas populares da região que precisavam de alfabetização e profissionalização e não fosse para o benefício econômico de quem já era abastado (ALB, 1894).

\footnotetext{
${ }^{5}$ ALB: Assembleia Legislativa da Bahia
}

Revista da ABPN • v. 12, n. Ed. Especial - Caderno Temático: "Africanos, escravizados, libertos biografias, imagens e experiências atlânticas” • agosto de 2020, p. 591-612 
No início do século XX, Antônio Bahia além de ser deputado e professor, também ocupou cargos de delegado da Instrução Pública da Bahia, Intendente interino de Salvador (equivalente ao cargo de prefeito interino) e diretor da Instrução Pública da Bahia (SOUZA, 1905). Ele ultrapassou os limites da sala da aula para defender a escolarização para as classes populares nas últimas décadas do século XIX e início do século XX, período de declínio do escravismo no país e do imediato pós abolição. Certamente, influenciou alguns de seus alunos, inclusive, tornando-se atuantes em causas sociais semelhantes as suas, assim como teve contato, colaborou na formação e também foi formado por outros professores na Escola Normal como possibilidade de qualificação e alcance de outros lugares sociais que não fossem o de subalternidade, como também fez Cincinato Franca, Francelino de Andrade e outros e outras docentes de sua época.

\section{CINCINATO RICARDO PEREIRA DA FRANCA}

Cincinato Ricardo Pereira da Franca foi outro personagem que empreendeu uma contundente luta abolicionista e pela educação de pessoas escravizadas e libertas. Defensor da liberdade e um entusiasta da educação como um instrumento de mudança de vida, foi um dos primeiros professores a declarar e efetivar seu envolvimento com a causa abolicionista na educação da Bahia. Nascido em Iguape, distrito de Cachoeira, região de Recôncavo baiano de grande destaque na produção açucareira desde século XVI, logo onde teve grande contingente de pessoas escravizadas e libertas, público alvo de sua atuação docente e político partidária como deputado (BARICKMAN, 2003).

Nas páginas do jornal $O$ Asteroide, Franca liderou a campanha pela libertação de pessoas escravizadas, sendo um de seus redatores. Foi um dos mais devotados abolicionistas de sua época, ao lado de outros que também compuseram diversas frentes para combater esse rechaço histórico que foi a escravidão na vida de muitas pessoas. Ele fazia parte do Clube Carigé, associação abolicionista em Cachoeira que também tinha figuras como Pedro Carigé, famoso por acoitar (esconder) pessoas escravizadas em fuga até conseguir a carta de alforria (SOUZA, 2010). Alguns professores e professoras, em algumas províncias, lecionaram e fizeram políticas também com o afã de possibilitar

Revista da ABPN • v. 12, n. Ed. Especial - Caderno Temático: "Africanos, escravizados, libertos biografias, imagens e experiências atlânticas” • agosto de 2020, p. 591-612 
pessoas ligadas ao cativeiro a aprenderem a ler, escrever e realizar cálculos básicos, como forma de saída da condição de analfabetismo e de alcançar outros lugares sociais, em um país com mais de $80 \%$ de analfabetismo. Condição que significaria uma formação considerável naquele contexto (CHALHOUB, 2003).

Cincinato Franca diplomou-se na Escola Normal em 1882, teve uma breve passagem como professor substituto em Salvador e em 1883 tornou-se professor efetivo em sua terra natal. Ele priorizou suas aulas noturnas que fundou em 1887 aos egressos da escravidão e escravizados. Tal medida não foi seguida por muitos outros professores na Bahia, que até podiam ser abolicionistas, mas que não declararam tal posicionamento ao abrir uma escola para lecionar à noite antes de 1888. O professor teve mais de cem alunos matriculados no ano de inauguração de sua escola noturna e com um posicionamento declarado em defesa não só da educação, mas do acesso de escravizados, libertos e ingênuos em espaços escolares de alfabetização (SANTOS, 2017).

Em 1891, Franca foi transferido para capital a convite da Intendência municipal, onde inicialmente lecionaria na escola primária da prisão de Salvador, mas não prosseguiu e em abril desse ano ficou à frente da escola masculina da Penha, uma freguesia da cidade (SOUSA, 2006). A escola se tornou o Grupo Escolar Rio Branco, que era um conjunto de escolas reunidas em um só prédio e que tinha também por diretor o professor Cincinato Franca. O Grupo Escolar Rio Branco era uma instituição de ensino reconhecida tanto pelo número de matriculados como pelos alunos bem avaliados nos exames finais (CAVALCANTE, 2015). O nome do Grupo Escolar era sugestivo em termos de questões ligadas à emancipação do escravismo, foi o nome da lei do ventre livre, em 1871.

O professor também produziu artigos e escreveu cartas que foram publicadas em jornais da cidade de Salvador acerca de questões raciais, educacionais e republicanas que defendia, assim como na cidade de Cachoeira. Em 1893, publicou um texto na Revista do Ensino Primário que se remeteu ao ensino técnico, leia-se educação para o trabalho, e a necessidade de sua oferta para as "classes laboriosas". Tratava o professor dos "desfavorecidos", do povo pobre e a necessidade de preparar esse contingente para as demandas do novo sistema político com a República. O professor criticava os esforços demandados para a formação bacharelesca e o esquecimento da formação técnica, o

Revista da ABPN • v. 12, n. Ed. Especial - Caderno Temático: "Africanos, escravizados, libertos biografias, imagens e experiências atlânticas" • agosto de 2020, p. 591-612 
ensino de uma profissão. Para ele, o ensino técnico "nobilita as classes laboriosas elevando a vida do trabalho aos olhos de todos". Ele destacou que "a ignorância gera a miséria e ela, muitas vezes, é a origem das paixões brutais", complementou afirmando que "só se combate a ignorância pela instrução" (FRANCA, 1893, p. 182-185).

Cincinato Franca também esteve engajado em política partidária, sua campanha para deputado estadual foi em 1910. Ele foi eleito em 1911 e mesmo com mandato legislativo continuou lecionando. Em 1914, encaminhou um ofício à Intendência de Salvador para solicitar a abertura de uma escola noturna no distrito da Penha, onde já lecionava durante o dia, pois alegou ter recebido um abaixo assinado de pessoas daquela localidade pedindo aulas à noite (FRANCA, 1914). Da mesma forma, assim como tantos outros pedidos nessa época, a Sociedade União de estivadores encaminhou ao intendente interino de Salvador, Antônio Bahia da Silva Araújo, em dezembro de 1915, um abaixo assinado de seus sócios pedindo a abertura de escola noturna para eles e seus filhos. O pedido foi atendido pelo colega professor Antônio Bahia e Franca abriu uma escola noturna voltada para o ensino primário (ARAÚJO, 1914). A escola noturna do professor Franca funcionava na localidade do Bogari, no distrito da Penha, tinha 20 alunos matriculados e 16 frequentavam. Entre os alunos frequentes, somente seis foram promovidos enquanto dez foram reprovados (MENDES, 1916, p.397).

O professor Cincinato Franca foi um professor engajado na defesa de melhores condições de ensino como também foi um crítico das condições precárias de trabalho do professorado municipal. Ele também manteve relações de proximidade com as autoridades municipais utilizando-se desses contatos para realizar pedidos voltados para o Grupo Escolar que dirigia e lecionava, ao mesmo tempo para pedir melhorias na educação em geral e tecer críticas quanto a situação do ensino primário.

O Grupo Escolar Rio Branco gozava de um reconhecimento positivo por parte dos moradores do distrito da Penha, das autoridades municipais e de grupos da imprensa. O professor Franca utilizava desse reconhecimento revertendo em ganhos políticos e para o grupo escolar. Examinando os periódicos é possível localizar o nome do professor Franca em eventos importantes, inclusive, com a recepção de intendentes municipal de Salvador. Ele esteve presente junto com seus alunos em eventos de exposição de trabalhos

Revista da ABPN • v. 12, n. Ed. Especial - Caderno Temático: "Africanos, escravizados, libertos biografias, imagens e experiências atlânticas" • agosto de 2020, p. 591-612 
escolares, onde intendentes e governadores prestigiavam a festividade. Os líderes políticos baianos utilizavam-se da presença de alunos e professores para demonstrar a sua atenção com dois temas sensíveis à população: as crianças e a educação. Já os professores aproveitavam dessa proximidade para fazerem pedidos, relatarem as suas queixas e reivindicarem melhorias nas condições de trabalho (SILVA, 2018).

Cincinato Franca não fugiu a essa estratégia, em 1913, uma comissão de alunos do Grupo Escolar Rio Branco esteve no gabinete do Intendente Júlio Brandão para solicitar uma máquina de escrever para auxiliar nos seus estudos. Após alguns dias, o pedido foi atendido, o professor, em ofício, agradeceu, fez elogios ao intendente e aproveitou para comentar a situação da instrução pública e a importância do professor primário. Ele lembrou de fatos como "o perigo do analfabetismo que nos amedronta e que emana todos os dissabores e desastres sociais, dependendo tudo diretamente da falta do ensino popular". Lembrando que a responsabilidade do ensino primário público cabia a intendência (JORNAL MODERNO, 1913).

Franca, prestigiado pela intendência municipal, foi indicado em dezembro de 1913 para presidir a comissão organizadora da Conferência Pedagógica da Bahia, evento que o professorado debatia sobre as práticas pedagógicas e as condições do ensino do estado (BRANDÃO, 2012). Franca tornava-se um professor cada vez mais respeitado e influente. Ele foi sócio do Instituto Geográfico da Bahia entre os anos de 1911 a 1915 e do conselho superior de ensino (MARTINS et al, 2019, p. 392).

No início do ano de 1918, aconteceu a greve do professorado municipal. A notícia de sua deflagração foi publicada na capa do jornal $A$ Tarde. Ao lado da notícia estava a foto do professor Franca com a legenda informando que ele também "foi vítima do calote, apesar de sua dedicação ao ensino das crianças”. O jornal e a foto buscaram dar maior relevância ao fato, uma vez que o professor era influente junto à sociedade, à categoria docente e às autoridades públicas. Essa foi uma de suas últimas atuações de grande abrangência. Ele atuou durante 44 anos na educação baiana, aposentando-se no ano de 1925 e vindo a falecer em 1934 (SILVA, 1942, p.59-61).

Franca foi um exemplo e inspiração de que a educação e a ocupação de espaços de poder, como assembleias legislativas e até o governo executivo são caminhos

Revista da ABPN • v. 12, n. Ed. Especial - Caderno Temático: "Africanos, escravizados, libertos biografias, imagens e experiências atlânticas" • agosto de 2020, p. 591-612 
prolíferos para combater e ultrapassar o racismo. Ele, embora não tenha sido o único e sem erros, foi construtor de poderoso capital intelectual e político. Foi propagador de uma escolarização ampla e considerável para população negra. Tudo isso em período crucial para identificar que a transição da vigência da escravidão para sua ilegalidade não garantiu o fim e a redução de estigmas raciais geradores de exclusões, mas nunca sem enfrentamentos tantos de anônimos (as) mais silenciosos (as) quanto de pessoas de mais visibilidades como "Cincinatos Francas" e "Antonios Bahias"

\section{Francelino de Andrade.}

Salvador padecia com graves crises educacionais nas primeiras décadas do século XX, embora desde a segunda metade do século XIX houvesse algumas iniciativas importantes a favor da escolarização dos mais pobres na Bahia por parte do poder público ou por iniciativa de alguns indivíduos. Atrasos nos pagamentos dos salários dos professores e péssimas condições físicas das escolas eram grandes problemas difíceis de se resolver a curto prazo. No entanto, alguns profissionais da educação se mobilizaram na tentativa de melhorar a qualidade da educação pública, fosse participando de congressos, propondo reformas de leis, escrevendo artigos, viajando para outros estados ou copiando seus modelos de ensino. Esses foram alguns dos esforços mobilizados pelo professor Francelino de Andrade, um "homem de cor".

Francelino do Espirito Santo Pereira de Andrade concluiu seus estudos na Escola Normal em dezembro de 1890 em uma turma de 19 estudantes, 15 do sexo feminino e 4 do sexo masculino (PEQUENO JORNAL, 1890, p1). Como a historiografia já demostrou, a presença majoritariamente feminina no magistério foi uma realidade muito comum em Salvador ao longo de toda a Primeira República, fato que se comprova quando destacamos a quantidade de formandas na turma do Andrade (LUZ, 2009).

Professor de gramática do ensino primário e conhecido no meio acadêmico de Salvador, Francelino de Andrade acumulou alguns cargos públicos na área da educação. Além de professor municipal, ele assumiu os cargos de Delegado Escolar em 1914, assim 
como Antônio Bahia também foi. Atuou também como Inspetor Municipal em 1915 no mesmo ano que Antônio Bahia era Intendente Municipal interino e Cincinato Franca atuava fortemente no Grupo Escolar Rio Branco, e também foi nomeado membro do Conselho Superior de Educação em 1924 (JORNAL DO COMÉRCIO, 1914).

Em 1915, o então inspetor municipal do ensino, Francelino de Andrade deu uma entrevista para o repórter do periódico A Notícia (1915), onde criticou o ensino primário na cidade e o modo como ele estava organizado. Francelino defendeu a reforma ou regulamentação do ensino: “o professor Francelino é pela reforma ou regulamentação, que, segundo afirma, será calcada nos moldes da neo-pedagogia e da pedagogia experimental". Na entrevista, Francelino explicou que não era competência do "executivo municipal" realizar a reforma ou regulamentação do ensino na cidade, disse ele que esta responsabilidade era do estado, segundo previa a constituição de 1891 (A NOTÍCIA, 1915).

Ocorre que sete anos depois da entrevista e de ter manifestado alguma esperança com a possível reforma no ensino primário, o professor escreveu um artigo em 1922, endereçado ao diretor do ensino municipal para comunicá-lo a respeito dos problemas que enfrentava o ensino primário naquele ano, principalmente, o aumento da população infantil. Além de manifestar sua preocupação como ensino primário no município, notase que Francelino de Andrade tinha respeito pelas celebrações cívicas como a independência do Brasil e da Bahia, ele fez parte de algumas comissões que organizavam a festa do 2 de julho na Bahia (DIÁRIO DE NOTÍCIAS, 1922).

O professor aproveitou a ocasião cívica e festiva em torno das comemorações pela independência do Brasil, em 1922, para manifestar seu desconforto com a situação da educação primária. Ele desejava muito que fosse aprovada a lei n.800 que regulamentava o ensino municipal primário. Para ele, esta lei, se aprovada, era "obra de patriotismo que em homenagem à Bahia já poderia vigorar no primeiro centenário do 2 de julho" (DIÁRIO DE NOTÍCIAS, 1923, p1).

No desenvolvimento da narrativa, o professor de gramática apontou os principais problemas da educação primária na década de 1920 na Bahia: a falta da criação de escolas que atendessem ao público infantil, falta de pagamentos aos professores, desorganização

Revista da ABPN • v. 12, n. Ed. Especial - Caderno Temático: "Africanos, escravizados, libertos biografias, imagens e experiências atlânticas" • agosto de 2020, p. 591-612 
pedagógica, falta de materiais didáticos para os professores trabalharem e a regulamentação do ensino municipal. As críticas destacadas por Francelino de Andrade era o reflexo da crise econômica que passava o estado da Bahia nesta década, mas, para ele, além da crise econômica, o que faltava aos governadores e autoridades políticas baianas era a vontade política de investimento na educação como observou José Augusto Ramos da Luz. (2009).

Diante de tamanhas dificuldades no ensino, Francelino de Andrade realizou uma pesquisa e com base em suas investigações elaborou um documento que mostrou ao intendente municipal: "a imperfeita distribuição das "delegacias escolares" e constatou que existia uma distância grande das escolas municipais em relação as casas dos estudantes. Sua pesquisa constatou também que a ajuda de custos para os delegados escolares (diretores de escolas) e os médicos que faziam a higiene nas escolas era "mesquinha e deprimente, o "salário" era cem mil réis mensais, adjunta aos seus honorários" (DIÁRIO DE NOTÍCIAS, 1923, p1).

Nos anos 1913, 1914 e 1915, aconteceu em Salvador as Conferências Pedagógicas que reuniram os professores primários da cidade. Segundo a historiadora Verônica Brandão (2012), nelas, os professores participavam ativamente, reivindicando, manifestando seu mal-estar em relação a situação das escolas ou reclamando a valorização da classe perante à sociedade da época. Em dezembro de 1913, ele fez parte da solenidade de abertura da Conferência junto com outros professores municipais, dentre eles, o já conhecido professor Cincinato Franca que neste ano foi o presidente da comissão organizadora do evento.

Francelino de Andrade escrevia ainda para duas revistas que circulavam no Rio de Janeiro, cuja temática se ligava aos temas da educação, política, letras e artes nas décadas de 1910 e 1920. Em 1913, ele escreveu o artigo: "O ensino da língua vernácula" para a revista Educação e Pediatria (1913-1917) que era dirigida pelos professores Franco Vaz e Álvaro Dias. Em 1926, escreveu o artigo: "Julgamentos da crítica literária" publicado pela revista Política, atualidades, questões sociais, letras e artes, no Rio de Janeiro. Portanto, era um intelectual que circulava em outros estados do país e que estava atento ao tema da escolarização, sobretudo, do ensino primário. 
Francelino de Andrade preservava valores nacionalistas, além de demonstrar forte interesse pela melhoria do ensino primário na cidade em que vivia. Ele próprio se orgulhava do fato de ser baiano de nascimento, valorizava às datas cívicas no estado e esteve envolvido em algumas comissões responsáveis pelas festividades do 2 de julho. Em 1923, foi pessoalmente entregar uma carta de protesto na redação do jornal Diário da Bahia. A carta era uma crítica contra o promotor de Santos, Tobias Bueno, que em uma audiência no tribunal classificou um réu de: "assassino, mulato e baiano". Vejamos o conteúdo da carta:

Baiano e mulato que sou, repilo com toda minha energia moral e fulminação idiota deste representante do ministério público. O seu estado de paranoico confunde na mesma sinonímia; assassino, mulato e baiano- denunciando o desgraçado réu sob esses três grandes crimes. Alto lá! Um grande baiano de cor preta, há pouco baixado ao túmulo, Manoel Querino, numa de suas excelentes obras de pesquisas históricas sentenciou: "O Brasil possui duas grandezas: a uberdade do solo e o talento do mestiço", ouça esta grande verdade e tome-a para seu governo (DIÁRIO DA BAHIA,1923, p1).

Ao se denominar "mulato", Francelino parece querer demonstrar que não tinha problemas em se identificar publicamente com um "homem de cor". Quando escreveu em 1923, crescia no Brasil os debates sobre raça, mestiçagem e identidade nacional. Muitos intelectuais de diferentes classes sociais e "raças" davam a sua versão sobre o Brasil e seu povo. Nesta citação, ficamos sabendo que o professor de gramática lia os textos do abolicionista, jornalista e professor militante Raimundo Manuel Querino falecido em 14 de fevereiro de 1923, nove dias antes do professor Andrade escrever a carta.

O professor não apenas lia os textos de Querino como também demonstrou ter admiração por este intelectual. A historiografia já apresentou a trajetória deste personagem importante para a história da Bahia. Quando este faleceu, foram vários os jornais da cidade que lhe prestaram homenagens. O Diário da Bahia destacou que em seus últimos anos de vida, Querino estava se dedicando a "concluir uma monografia exaustiva sobre as festas do 2 de julho, desde às suas origens, tendo conseguido obter os

Revista da ABPN • v. 12, n. Ed. Especial - Caderno Temático: "Africanos, escravizados, libertos biografias, imagens e experiências atlânticas” • agosto de 2020, p. 591-612 
desenhos dos primeiros palanques erguidos para essas comemorações cívicas" (HELEN, GLEGHILL, p113).

Manuel Querino é considerado pela historiografia um intelectual negro pioneiro nos estudos sobre a importância da contribuição cultural e civilizacional dos africanos no Brasil. Ele defendia a tese de que foi o "trabalho do negro que aqui sustentou por séculos e sem desfalecimento a nobreza e a prosperidade do Brasil". Nesse sentido, ele escreveu em 1916 A raça africana e seus costumes na Bahia, e dois anos depois; O colono preto como fator da civilização brasileira, dois textos em que Querino apresenta suas ideias acerca da formação da nacionalidade brasileira e da importância política, social e cultural da "raça negra" no Brasil. Francelino de Andrade leu os textos de Querino e pareceu entender a proposta do autor. Para defender os baianos das ofensas do promotor público de Santos, o professor de gramatica cita ainda outro importante personagem para a história da Bahia, o político Ruy Barbosa. "Quanto à falsa semiologia de "baiano" ratear por assassino, atiro-lhe em desafio à sua estultice, sr. promotor, isto, só isto: a Bahia é o "verde ninho murmuroso" da maior força verbal do mundo- Rui Barbosa". (VASCONCELOS, 2009, p.142).

Manuel Querino e Ruy Barbosa, as duas importantes referências para Francelino de Andrade assumiram posições políticas diferentes quando esteve em pauta o lugar dos "homens de cor" na sociedade brasileira em fins do século XIX. Ruy Barbosa entendia que a "raça emancipada", ou seja, "os homens de cor"; "eram corações iludidos, feitichistas, presos às crenças próprias, aos inconscientes”. Esta crítica era direcionada à existência da Guarda Negra, uma organização de homens pretos surgida logo após a lei de abolição da escravidão e que tinha por finalidade proteger a família real, sobretudo, a pessoa da princesa Isabel. Nesse sentido, Barbosa entendia que a "raça emancipada" não tinha condições intelectuais e culturais para dirigir politicamente os rumos do Estado no pós-abolição. Ao contrário do que pensava e escrevia o professor Manoel Querino, que defendia e valorizava as contribuições civilizacionais dos africanos no Brasil (ALBUQUERQUE, 2009, p.241).

Mas quando escreveu a carta, o professor não parece que estava preocupado com as posições políticas e ideológicas dos baianos citados em relação ao que eles entendiam 
sobre os rumos dos "homens de cor" na sociedade brasileira. Ao citá-los, parece querer demonstrar que na Bahia existiam homens com capacidades intelectuais e culturais de alto nível. Portanto, sua intenção era demonstrar para o autor da ofensa, o promotor público de Santos, que sua concepção em relação aos baianos estava equivocada, assim como buscou em tantas tentativas acerca do tratamento dado das autoridades governamentais à Instrução Pública na Bahia, assim como Antônio Bahia, Cincinato Franca e tantos outros docentes que não tiveram tantos espaços de publicar seus objetivos, questionamentos e lutas em prol das camadas populares e negras da sociedade baiana.

Francelino de Andrade teve uma trajetória longa e de muito trabalho na área do magistério. Ele ocupou cargos diferentes enquanto funcionário público. Em 1929, candidatou-se a deputado estadual obtendo 2.018 votos, foi o nono melhor votado, mas não tomou posse, já que só eram diplomados os sete melhores posicionados (ALBA, 1929). Ele viveu em uma cidade que padecia com graves problemas no campo da educação formal e consciente destes problemas mobilizou suas energias para tentar encontrar soluções. Participava de congressos, escrevia artigos, propunha leis, viajava para outros estados para discutir temas ligados à educação, foi um conjunto de ações que demonstram a sua militância como educador. $\mathrm{O}$ desfecho de sua trajetória na educação como docente e como cidadão ainda não ficou evidente a esta pesquisa, mas sua marca enquanto sujeito que buscou com veemência oportunidades de educação para sujeitos que não integravam elites econômicas e intelectuais no pós abolição ficou registrada nos anais da história da Instrução Pública da Bahia e do Brasil.

\section{CONSIDERAÇÕES FINAIS}

É possível que os três professores destacados neste artigo tenham se encontrado, discutido, trocado informações e colaborado para formações mútuas de alguma maneira, juntamente com outros e outras docentes que tinham formas de atuação muito próximas. Embora tenham feito parte de três gerações distintas, eles se formaram professores pela Escola Normal e atuavam em favor da escolarização, sobretudo, das classes pobres. Estiveram próximos em algumas situações da vida docente, como nas Conferências 
Pedagógicas realizadas em Salvador nos anos 1913, 1914 e 1915, o que reforça a hipótese de encontros e influências entre os três.

Ratificamos que esses professores se destacaram por agirem em questões sociais para além da vida profissional, através de anos de mobilizações em prol de grupos da sociedade que eram fortemente prejudicados em condições econômicas, sociais e raciais! Em alguma medida, manifestaram conexões e movimentos de superação da escravidão em paralelo ao processo de construção da ideia de que a educação escolar era algo indispensável aos sujeitos das camadas populares.

\section{DOCUMENTAÇÃO CITADA}

A Notícia, 24/04/1915, p.1. Hemeroteca Digital Brasileira da Biblioteca Nacional

A Manhã, 04/07/1920, p.1 Hemeroteca Digital Brasileira da Biblioteca Nacional. Ata da eleição 07/03/1929- livro 1237. Seção Legislativa, Arquivo Público do Estado da Bahia.

COLEÇÃO de Leis do Império do Brasil (1878). Decreto $\mathrm{n}^{\circ}$ 7.031-A, de 6 de setembro de 1878. Disponível em: <http://www2.camara.leg.br/legin/fed/decret/18241899/decreto-7031-a-6-setembro-1878-548011-publicacaooriginal-62957-pe.html>

Acessado em: 10 maio 2020.

COLEÇÃO de Leis do Império do Brasil (1879). Decreto n 7.274, de 1879. Disponível em: <https://www2.camara.leg.br/legin/fed/decret/1824-1899/decreto-7247-19-abril1879-547933-publicacaooriginal-62862-pe.html> Acessado em: 10 maio 2020.

Francisco Gonçalves Martins. Relatório do Presidente da Província da Bahia, em 1869. Disponível em: <http://brazil.crl.edu/bsd/bsd/136/000030.html> Acessado em: 10 de maio de 2020.

Jornal do Comercio $(R J), 10 / 03 / 1914$

Jornal Moderno 23 e 30 de agosto de 1913

Mensagens do governador da Bahia para a Assembleia Legislativa. Governador José Marcelino de Souza. Site: <http://memoria.bn.br/DocReader/872989/1349?pesq=\%22Antônio\%20Bahia\%20da\%2 0Silva\%20Araújo\%22> Acessado em 11 de maio de 2020.

Pequeno Jornal, 13/12/1890, p. 1 Hemeroteca Digital Brasileira da Biblioteca Nacional

Revista da ABPN • v. 12, n. Ed. Especial - Caderno Temático: "Africanos, escravizados, libertos biografias, imagens e experiências atlânticas” • agosto de 2020, p. 591-612 
Revista Educação e Pediatria, Ano 1913, p.29. Revista- Política, atualidade, questões sociais, letras e artes (RJ), 05/06/1926, p.9

\section{REFÊNCIAIS BIBLIOGRÁFICAS}

ALBUQUERQUE, Wlamyra R. O Jogo da dissimulação: abolição e cidadania negra. São Paulo: Companhia das Letras, 2009.

ARAÚJO, Carlos Moreira de; GOMES, Flávio dos Santos (orgs). Rascunhos Cativos: educação, escolas e ensino no Brasil escravista. Rio de Janeiro: Letras/Faperj, 2017.

BRANDÃO, Verônica de Jesus. Práticas curriculares nas escolas públicas primárias: um estudo das teses apresentadas nas Conferências pedagógicas de Salvador (1913-1915). Dissertação apresentada ao Programa de Pós-Graduação em Educação e Contemporaneidade da Universidade do Estado da Bahia, UNEB. Salvador, 2012.

BARICKMAN, Bert Jude. Um Contraponto baiano: açúcar, fumo, mandioca e escravidão no Recôncavo (1780 - 1860). Rio de Janeiro: Civilização Brasileira, 2003.

BARROS, Surya Aaronovich Pombo de. "Negrinhos que por ahi andão": a escolarização da população negra em São Paulo (1870-1920). Dissertação apresentada ao Programa de PósGraduação em Educação - Faculdade de Educação / Universidade de São Paulo, São Paulo, 2005.

CARVALHO, José Murilo de. A vida política. In: CARVALHO, José Murilo de (org.). História do Brasil nação (1808-2010): A construção nacional. Rio de Janeiro: Editora Objetiva, Fundação Mapfre, 2003.

CAVALCANTE, Ian A. Pela instrução dos filhos do povo: escolarização e cultura escolar na Salvador do pós-abolição, 1888-1906. Dissertação de Mestrado em Educação pelo programa da Pós-Graduação da UFF, Niterói, 2015.

CONCEIÇÃO, Miguel Luiz da. O aprendizado da liberdade: educação de escravos, libertos e ingênuos na Bahia oitocentista. Dissertação apresentada ao Programa de Pós-Graduação em História, Faculdade de Filosofia e Ciências Humanas, Universidade Federal da Bahia, Salvador, 2007.

FARIA FILHO, Luciano Mendes. Dos pardieiros aos palácios: cultura escolar e urbana em Belo Horizonte na Primeira República. Passo Fundo: UPF Editora, 2000.

FERREIRA, Higor Figueira. Em tintas negras: Educação, ensino e a trajetória de Pretextato dos Passos e Silva na Corte Imperial - Novas evidências. Revista ABPN, v. 10, p. 26-42, 2018.

FONSECA, Marcus Vinícius e BARROS, Surya Pombo de (Org). A história da educação dos negros no Brasil. Niterói: EDUFF, 2016.

FONSECA, Marcus Vinícius. A educação dos negros: uma nova face do processo de abolição da escravidão no Brasil. Bragança Paulista: EDUSF, 2002.

Revista da ABPN • v. 12, n. Ed. Especial - Caderno Temático: "Africanos, escravizados, libertos biografias, imagens e experiências atlânticas" • agosto de 2020, p. 591-612 
FRAGA FILHO, Walter. Encruzilhadas da liberdade. História de escravos e libertos na Bahia (1870-1910). Campinas: Editora da Unicamp, 2006.

GLEGHILL, Helen Sabrina. Travessias racialistas no atlântico negro: reflexões sobre Booker $T$. Washington e Manuel R. Querino. Tese apresentada ao Programa Multidisciplinar de Estudos Étnicos e Africanos da Faculdade de Filosofia e Ciências Humanas, UFBA, Salvador, 2014.

GONDRA, José; SCHUELER, Alessandra Frota. Educação, Poder e Sociedade no Império Brasileiro. São Paulo: Cortez, 2008.

LOPES, Katia Geni Cordeiro. A presença de negros em espaços de instrução elementar da cidade-corte: O caso da Escola da Imperial Quinta da Boa Vista. Dissertação de mestrado Programa de Pós-Graduação em Políticas Públicas - Universidade do Estado do Rio de Janeiro, 2012.

LUCINDO, Willian Robson Soares. Educação do pós-abolição: Um estudo sobre as propostas educacionais de afrodescendentes (SÃO PAULO/1918-1931). Editora: Casa aberta, Florianópolis, 2010.

LUZ, Carlos Augusto. Um olhar sobre a educação na Bahia: a salvação pelo ensino primário (1924-1928). Tese apresentada ao Programa de Pós-Graduação em História Social da Universidade Federal da Bahia. Salvador, 2009.

LUZ, Itacir Marques da. Compassos letrados: Profissionais negros entre instrução e ofício no Recife (1840-1860). Dissertação apresentada ao Programa de Pós-Graduação em Educação, Universidade Federal da Paraíba. João Pessoa, 2008.

MAC CORD, Marcelo. Artífices da cidadania: mutualismo, educação e trabalho no recife oitocentista. Campinas. SP: Ed Unicamp, 2012.

MENDES, Antônio Pacheco. Relatório apresentado ao Conselho Municipal do Estado da Bahia. Seção de obras do "O Democrata". Bahia. 1916.

MARTINS, Wilson Thomé Sardinha; SILVA, Nilson João; PEREIRA, José Nilton Carvalho. Síntese Histórica: 125 anos do Instituto Geográfico Histórico da Bahia (1894-2019). Ed. Allucci e Associados Comunicações. Salvador. 2019

PERES, Eliane. Templo de Luz: Os Cursos noturnos masculinos de Instrução primária da Biblioteca Pública Pelotense 1875 - 1915. Pelotas: Seiva publicações, 2001.

SANTOS, Jucimar Cerqueira dos Santos. Escolas noturnas para trabalhadores na Bahia (18701889). Dissertação pelo Programa de Pós-Graduação em História Social da Universidade Federal da Bahia. Salvador, 2017.

SILVA, Adriana Maria Paula da. Aprender com perfeição e sem coação: uma escola para meninos pretos e pardos na Corte. Brasília: Editora Plano, 2000.

SILVA, Alexandra Lima da. "Avisem que estamos chegando": a história do escravizados que fundou uma escola no Rio de Janeiro. Site: https://www.geledes.org.br/avisem-que-estamos-

Revista da ABPN • v. 12, n. Ed. Especial - Caderno Temático: "Africanos, escravizados, libertos biografias, imagens e experiências atlânticas” • agosto de 2020, p. 591-612 
chegando-a-historia-do-escravizado-que-fundou-uma-escola-no-rio-de-janeiro/. Acessado em 15 de junho de 2020 .

SILVA, Fabiano Moreira da. Professorado municipal de Salvador: queixas, crises e greves (1912-1918). Dissertação apresentada ao Programa de Pós-Graduação em História Social da Universidade Federal da Bahia. Salvador, 2017.

SILVA, Luara dos Santos. "Etymologias preto": Hemetério José dos Santos e as questões raciais do seu tempo (1888 - 1920). Dissertação de mestrado apresentado ao programa de Pós-graduação em Relações Etnicorraciais do CEFET/RJ, Rio de Janeiro, 2015.

SILVA, Pedro Celestino. Prof. Cincinato Ricardo Pereira da Franca. In: Revista do Instituto Geográfico e Histórico da Bahia, nº 68. 1942, p.59-61.

SOUSA, Ione Celeste Jesus de. Escolas ao Povo: experiências de escolarização de pobres na Bahia-1870 a 1890. Tese de doutorado pelo Programa de Pós-graduação. São Paulo: PUC-SP, 2006 (Tese de Doutorado)

SOUZA, Jacó dos Santos. Vozes da Abolição: escravidão e liberdade na imprensa abolicionista cachoeirana (1887-1889). Dissertação de mestrado pelo programa de Pós-graduação em História. Santo Antônio de Jesus. UNEB.2010.

VASCONCELLOS, Christianne Silva. O uso de fotografias de africanos no estudo etnográfico de Manuel Querino. Sankofa. Revista de História da África e de estudos da Diáspora Africana, n.4, dezembro, 2009;

Recebido 03/07/2020

Aprovado em 22/07/2020

Revista da ABPN • v. 12, n. Ed. Especial - Caderno Temático: "Africanos, escravizados, libertos biografias, imagens e experiências atlânticas" • agosto de 2020, p. 591-612 